\title{
Assessment of Abrasion-Induced Visual Defects in Twin Screw Wet Granulation Using Wall Friction Measurements
}

\author{
Judith Menth ${ }^{1,2}$, Martin Maus ${ }^{1}$ and Karl G. Wagner ${ }^{2,3}$ \\ Received 16 April 2021; accepted 13 September 2021; published online 4 January 2022

\begin{abstract}
Starting point of the presented study were abrasion effects occurring during a twin screw wet granulation (TSG) process of a new chemical entity (NCE) formulation, resulting in gray spots on the final tablets. Several actions and systematic changes of equipment defect rate of the tablets, i.e., gray spots on the surface, below the specification limit. To understand the rationale and mechanism behind these improvements, correlations of defect rates and wall friction measurements using a Schulze ring shear tester were evaluated. To check the suitability of the method, a broad range of wall materials as well as powder formulations at various moisture levels were investigated with regard to their wall friction angle. As differences in wall friction angle could be detected, further experiments were conducted using wall material samples made out of different screw materials for TSG. Evaluation of these screw wall material samples gave first hints, which screw materials should be preferred in regard of friction for TSG process. In the finally presented case study, wall friction measurements were performed using the above mentioned NCE formulation with known abrasion issues at TSG processing. The results confirmed that changes which led to a reduced visual defect rate of tablets correlated with a decreased wall friction angle.
\end{abstract} \\ and process parameter settings of TSG process were conducted which reduced the visual \\ The results suggest wall friction measurements as a potent tool for equipment selection and \\ establishment of a suitable process window prior to conducting TSG experiments.
}

KEY WORDS: abrasion, twin screw granulation, wall friction, ring shear tester, continuous granulation

\section{INTRODUCTION}

The aim of pharmaceutical production is to always result in a final drug product of the desired quality. Key for this aim is proper process understanding, including potential issues and their associated risks, which may occur during a pharmaceutical process. For twin screw granulation, one important process immanent factor is friction. For good, to

Guest Editors: Feng Zhang, Michael Repka and Suresh Bandari

${ }^{1}$ Pharmaceutical Development, Boehringer Ingelheim Pharma GmbH \& Co. KG, Birkendorfer Straße 65, 88397 Biberach, Germany

${ }^{2}$ Department of Pharmaceutical Technology, University of Bonn, Gerhard-Domagk-Straße 3, 53121 Bonn, Germany

${ }^{3}$ To whom correspondence should be addressed. (e-mail: karl.wagner@ uni-bonn.de) facilitate dispersive and distributive mixing [1], but also for bad in case pronounced abrasion of screw and/or barrel material occurs. To understand and balance the effect of friction, a supportive method should facilitate a more rational selection of equipment and process settings. To evaluate friction effects between powders and equipment, wall friction measurements are supposed by many authors [2-13]. The measured parameter describing the friction between a powder and a (equipment) surface is the wall friction angle, which is accessible by various wall friction testers described in literature $[2,6,12,14]$. Amongst the listed, the Schulze ring shear tester offers easy handling of small sample sizes (appr. $10 \mathrm{~g}$ for wall friction measurement) at reduced measuring periods [14] and was therefore selected to be used in this study. Apart from this practical considerations, Schulze described the big advantage of 
ring-shaped shear cells as they allow to apply a not limited shearing path [15]. One common application wall friction testers are used for is the design of silos. Bradley et al. [4], Jager et al. [11], and Prescott et al. [13] pointed out the importance of the knowledge about wall friction to guarantee mass flow inside a silo or bin.

In addition, several authors have investigated the influence of either powder material or wall material attributes on the wall friction angle. Fekete et al. [5], Halford et al. [7], and Iqbal et Fitzpatrick [10] described the impact of powder moisture on resulting wall friction angle in their work. In general, they all found the effect of increasing wall friction at increasing moisture level of the powder. Additionally, Fekete et al. found a pronounced decrease of that relationship exceeding a certain moisture level [5] and Halford et al. found the described relationship especially at a lower normal pressure [7]. Bradley et al. could show the correlation of increasing relative wear of different steel materials with increasing wall friction angle [3]. Han [8] found lower wall friction angles for polished steel compared to non-polished samples.

The interaction of powder and process dependence on friction, adhesion, and cohesion phenomena are mostly described for the tableting process [16-19].

Nakamura et al. used a shear stress measurement device for predicting the sticking tendency of powder to the punch using friction measurements [18], which might be mechanistically similar to phenomena observed in twin screw granulation.

Inspired by the above described works, the presented work focuses on the twin screw wet granulation process. Twin screw (wet) granulation has been gaining more and more interest within the last years as it offers the possibility of a continuous way to perform wet granulation which result in several advantages, e.g., reduced footprint, higher flexibility, and increase of product quality by diversion of bad fraction material [20]. Focus within this study was set on how abrasion effects potentially occurring during that process can be explained using wall friction measurements. Regarding abrasion process/equipment settings as well as formulation aspects have to be considered to be potential impact factors. The screw configuration is one important equipment setting affecting friction effects inside the twin screw granulator. Simple conveying elements as well as kneading elements are commonly used screw elements for TSG process [21]. Stauffer et al. already considered a temperature increase along the barrel to be proportional to granulator power consumption and friction forces [1] in the zones where kneading elements were applied. Kumar et al. found an increase of torque with the increasing number of kneading elements being added to the screw [22]. That clearly shows that higher friction forces are generated by adding kneading elements to the simple conveying elements. Important formulation aspects are the filler combination as well as the selection of binder. The two binders being used within this study are Copovidone and HPMC. Higher binder evectiveness of Povidone compared to HPMC regarding granulation process was found by different researchers [23, 24]. Nevertheless, Vandevivere et al. did not find a correlation between binder effectiveness and torque within their study [24].

Explanation of friction forces occurring inside the twin screw granulator at distinct equipment and process parameter settings of TSG and for several formulations as well as the correlation of the impact of these parameters on wall friction angle is the aim of this paper. Therefore, wall friction measurements were performed using a Schulze ring shear tester, investigating the impact of various wall/screw materials, powder blends, moisture levels, and normal stress levels. The obtained impacts will be applied to a NCE case study to explain the empirical process optimization in respect of reduced material abrasion and subsequently, limited visual defects on resulting tablets.

\section{MATERIAL AND METHODS}

\section{Material}

\section{Formulation 1}

Formulation 1 was based on the two fillers Mannitol (MAN, Pearlitol $50 \mathrm{C}$, Roquette $\mathrm{GmbH}$ ) and microcrystalline cellulose (MCC, Avicel PH-101, FMC Biopolymer) in a ratio of $2: 1(\mathrm{w} / \mathrm{w})$. For this formulation, a placebo and an active preblend were prepared. For the active formulation, Acetaminophen micronized (APAP, Paracetamol micronized, Mallinckrodt Pharmaceuticals) at a drug load $\mathrm{DL}=5 \%$ was added as a model active pharmaceutical ingredient (API). The entire amount of the binder Hypromellose (HPMC, Methocel E5 - LV USP/EP Prem., Dow Chemical Company) and half of the amount of the disintegrant Crospovidone (CROS, Kollidon CL-SF, BASF SE) were added to the preblend consisting of APAP (only for the active formulation), MAN, and MCC, to result in the intragranular phase. This preblend was used for the investigation of wall friction angle via the ring shear wall friction method as described later. The detailed composition of formulation 1 including the extragranular phase is described in Table I.

\section{Formulation 2}

Comparable to formulation 1, a placebo as well as an active formulation including APAP at a DL $=5 \%$ as model API were prepared for formulation 2 . This formulation was based on 
Table I Composition of Formulation 1 (Placebo and Active)

\begin{tabular}{llll}
\hline Excipient/API & $\begin{array}{l}\text { Placebo: } \\
\text { weight } \\
\text { percent- } \\
\text { age } \\
{[\%(\mathrm{w} / \mathrm{w})]}\end{array}$ & $\begin{array}{l}\text { Active: } \\
\text { weight } \\
\text { percent- } \\
\text { age } \\
{[\%(\mathrm{w} / \mathrm{w})]}\end{array}$ & Function - formulation part \\
& - & 5.0 & API-intragranular \\
\hline APAP & 63.0 & 59.7 & filler-intragranular \\
MAN & 31.5 & 29.8 & filler-intragranular \\
MCC & 1.5 & 1.5 & binder - intragranular \\
HPMC & 1.5 & 1.5 & disintegrant-intragranular \\
CROS & 1.5 & 1.5 & disintegrant-extragranular \\
CROS & 1.0 & 1.0 & lubricant - extragranular \\
MGST & & &
\end{tabular}

Abbreviations: APAP, Paracetamol micronized; MAN, Mannitol; MCC, Microcrystalline cellulose; HPMC, Hypromellose; CROS, Crospovidone; MGST, Magnesium stearate

the two fillers MAN and Starch undried (STA, Maisstärke extra-weiss, Roquette $\mathrm{GmbH})$ in a ratio of 9:1 (w/w). For wall friction measurements, Copovidone (COPV, Kollidon VA 64, BASF SE) as a binder, and CROS, as disintegrant, were added to the intragranular phase. Table II gives an overview of the composition of formulation 2 also including the extragranular phase.

\section{BIxx1 formulation}

Within the case study, a formulation including the NCE BIxx1 (blinded API, Boehringer Ingelheim Pharma GmbH $\&$ Co.KG) at a $\mathrm{DL}=20 \%$ was evaluated. The formulation consisted mainly of the two fillers MAN and MCC; COPV was added as a binder. Highly dispersed silicon dioxide (SIL; CAB-O-SIL M5P, Cabot Rheinfelden GmbH \&

Table II Composition of Formulation 2 (Placebo and Active)

\begin{tabular}{llll}
\hline Excipient/API & $\begin{array}{l}\text { Placebo: } \\
\text { weight } \\
\text { percent- } \\
\text { age } \\
{[\%(w / w)]}\end{array}$ & $\begin{array}{l}\text { Active: } \\
\text { weight } \\
\text { percent- } \\
\text { age } \\
{[\%(w / w)]}\end{array}$ & Function - formulation part \\
& - & 5.0 & API-intragranular \\
& 82.8 & 78.3 & filler-intragranular \\
APAP & 9.2 & 8.7 & filler-intragranular \\
MAN & 4.0 & 4.0 & binder - intragranular \\
STA & 1.5 & 1.5 & disintegrant-intragranular \\
COPV & 1.5 & 1.5 & disintegrant - extragranular \\
CROS & 1.0 & 1.0 & lubricant - extragranular \\
CROS & &
\end{tabular}

Abbreviations: APAP, Paracetamol micronized; MAN, Mannitol; STA, Starch undried; COPV, Copovidone; CROS, Crospovidone; MGST, Magnesium stearate
Co.KG) improved the flowability and half of the amount of CROS was added to the intragranular phase as disintegrant. A detailed composition is given in Table III.

\section{METHODS}

\section{Preparation of Powder Preblends}

\section{Placebo Preblends - Formulation 1 and Formulation 2}

For each of the two placebo formulations (see Tables I and II), a powder preblend of $73.125 \mathrm{~kg}$ was prepared. All intragranular excipients were sieved through a $1.016 \mathrm{~mm}$ grater holed screen with a Comil 197 S (Quadro Engineering, Canada) at a rotator speed of $1510 \mathrm{rpm}$. In a second step, the intragranular excipients were blended in a $400 \mathrm{~L}$ container freefall blender (Servolift $\mathrm{GmbH}$, Germany) at a rotation speed of $10 \mathrm{rpm}$ for $15 \mathrm{~min}$.

\section{Active Preblends - Formulation 1 and Formulation 2}

An amount of $97.5 \mathrm{~kg}$ of powder preblend was prepared for each of the two active formulations (see Tables I and II). All intragranular excipients except MAN (i.e., MCC, HPMC, CROS for formulation 1; STA, COPV, CROS for formulation 2) were mixed with APAP in a 400-L container freefall blender (Servolift, GmbH, Germany) at a rotation speed of $10 \mathrm{rpm}$ for $5 \mathrm{~min}$. After the blending step, the premix was sieved together with the MAN through a $1.016 \mathrm{~mm}$ grater holed screen with a sieving machine. The sieving machine was a Comil 196/2 (Quadro Engineering, Canada) running at a rotator speed of $630 \mathrm{rpm}$ for formulation 1 and a Comil 197S (Quadro Engineering, Canada) running at a rotator speed

Table III Composition of the Case Study Formulation Including BIxx1

\begin{tabular}{lll}
\hline Excipient/API & $\begin{array}{l}\text { Weight percent- } \\
\text { age } \\
{[\%(\mathrm{w} / \mathrm{w})]}\end{array}$ & $\begin{array}{l}\text { Function -formulation part } \\
\text { BIxx } 1\end{array}$ \\
MAN & 20.0 & API-intragranular \\
MCC & 47.0 & filler - intragranular \\
COPV & 23.5 & filler-intragranular \\
SIL & 2.5 & binder - intragranular \\
CROS & 1.0 & glidant-intragranular \\
CROS & 2.5 & disintegrant-intragranular \\
MGST & 2.5 & disintegrant-extragranular \\
\hline
\end{tabular}

Abbreviations: APAP, Paracetamol micronized; MAN, Mannitol; MCC, Microcrystalline cellulose; COPV, Copovidone; SIL, Highly dispersed Silicon dioxide; CROS, Crospovidone; MGST, Magnesium stearate 
of $1510 \mathrm{rpm}$ for formulation 2. Finally, all intragranular excipients including the API were blended at a rotation speed of $10 \mathrm{rpm}$ for $10 \mathrm{~min}$ in the same $400 \mathrm{~L}$ container freefall blender.

\section{BIxx1 Formulation}

For the case study of the BIxx 1 formulation, $8.2 \mathrm{~kg}$ of powder preblend were prepared. In a first step, MAN was sieved through a 1.016-mm grater holed screen using a Comil U5 (Quadro Engineering, Canada) at a rotator speed of $1670 \mathrm{rpm}$. Subsequently, all excipients were blended in a $40 \mathrm{~L}$ container freefall blender (Servolift GmbH, Germany) at a rotation speed of $10 \mathrm{rpm}$ and a blending time of $32 \mathrm{~min}$. The resulting excipient premix was sieved through a $1.016 \mathrm{~mm}$ grater holed screen using a Comil U5 (Quadro Engineering, Canada) at a rotator speed of $1670 \mathrm{rpm}$. In the next step, BIxx1 was added to the sieved excipients premix. Finally, the excipients premix plus BIxx1 were blended in a 40-L container freefall blender (Servolift $\mathrm{GmbH}$, Germany) at a rotation speed of $10 \mathrm{rpm}$ for another 32 min resulting in the final powder preblend.

\section{Wall Friction Measurement with a Ring Shear Tester}

\section{Method Description - Wall Friction Measurement}

Wall friction measurement was performed using a Schulze ring shear tester RST-XS.s (Dr.-Ing. Dietmar Schulze Schüttgutmesstechnik, Germany). Measurements were carried out as described by Schulze [15]. A small layer of powder is being sheared across the respective wall material sample, which is placed as insert at the bottom of the shear cell. The shear cell is rotated slowly with a certain angle velocity $\omega$ while applying a certain normal stress $\sigma_{w}[\mathrm{~Pa}]$ on the system (see Fig. 1).

Two force sensors record the forces $F_{1}$ and $F_{2}$ resulting in the shear stress $\tau_{w}[\mathrm{~Pa}]$. By plotting the shear stress $\tau_{w, n}[\mathrm{~Pa}]$ against normal stress $\sigma_{w, n}[\mathrm{~Pa}]$, a wall yield locus is obtained (see Fig. 2); finally, the wall friction angle $\varphi_{w, n}(\mathrm{WFA})\left[^{\circ}\right]$ per normal stress $\sigma_{w, n}[\mathrm{~Pa}]$ is calculated according to Eq. (1) described by Behres et al. [14].

$$
W F A \varphi_{w, n}=\arctan \left(\frac{\tau_{w, n}}{\sigma_{w, n}}\right)
$$

Hancock mentioned the typical correlation of normal stress $\sigma_{w}[\mathrm{~Pa}]$ and WFA $\varphi_{w}\left[^{\circ}\right]$ for pharmaceutical bulks where WFA increases at decreasing normal stress (see also Fig. 2) [9].
Fig. 1 Setup of Schulze ring shear tester for wall friction angle measurement (from Schulze [25])

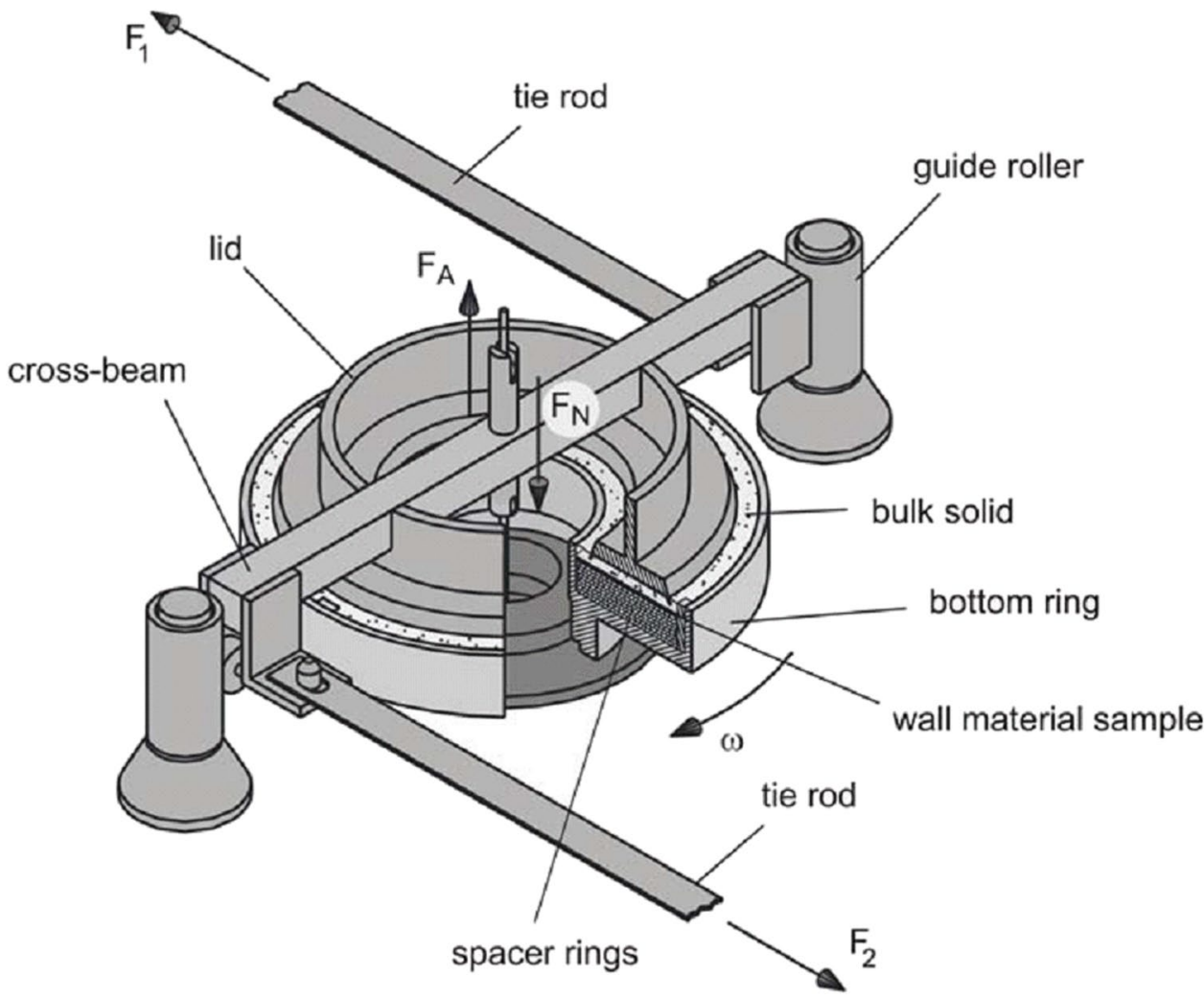


Fig. 2 Relationship between shear stresses $\tau_{w}$ and normal stresses $\sigma_{w}$ resulting in a specific wall yield locus and wall friction angle ( modified from Schulze [25]), reduced wall friction angle at increased normal stress (index 1-3)

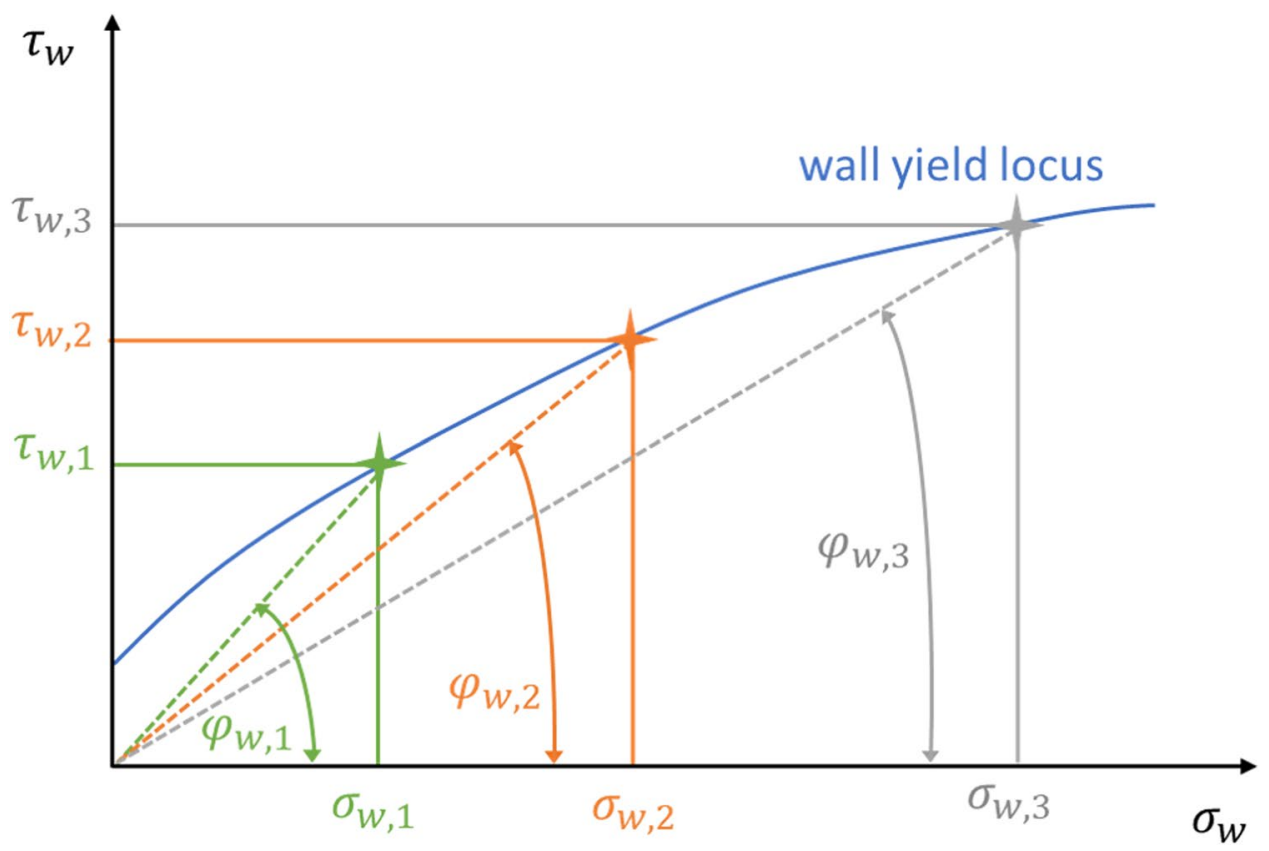

\section{Method Description - Testing Procedure}

For the wall friction measurements presented in this paper, eight normal stresses $\sigma_{w}[\mathrm{~Pa}]$ were applied in a range of $200 \mathrm{~Pa}$ and $4000 \mathrm{~Pa}$. Measurement points were exponentially distributed: $\sigma_{w} 1=4000 \mathrm{~Pa}, \sigma_{w} 2=2396 \mathrm{~Pa}, \sigma_{w} 3=1453 \mathrm{~Pa}$, $\sigma_{w} 4=898 \mathrm{~Pa}, \sigma_{w} 5=571 \mathrm{~Pa}, \sigma_{w} 6=379 \mathrm{~Pa}, \sigma_{w} 7=266 \mathrm{~Pa}$, $\sigma_{w} 8=200 \mathrm{~Pa}$. Within one measurement, this cycle of eight different normal stresses was repeated four times. The average WFA $\varphi\left[{ }^{\circ}\right]$ in the presented results is the average value of these four repetitions per normal stress $\sigma_{w}$. WFA were measured for the different formulations and their interaction with different wall/screw materials. Furthermore, in addition to the established method to evaluate dry powders and their friction effects on different wall and screw materials, also wet granules (wetted powder) were evaluated comparably. The preparation of the wet granule mass for the wall friction measurement is described later.

\section{Wall/Screw Materials}

Two sets (named "set 1" or "set 2" in the following) of wall material samples were used for the evaluation in the ring shear tester with regard to their interaction with the formulations described previous.

Three different materials with specific surface treatments were chosen to be included into set 1 . Intention for the selection of set 1 materials was to evaluate whether the described wall friction method can differentiate between presumably highly different wall materials and the resulting wall friction of different formulations and moisture levels. Surface roughness of all wall materials (set 1 and set 2) was measured using a MahrSurf M 300 (Mahr GmbH, Germany). The measured roughness Ra was chosen as reference parameter for the surface roughness of each wall material.

Table IV gives an overview of the wall material samples of set $1=$ proof of feasibility set.

In contrast to set 1 , wall material sample set 2 consisted of more similar, but still different screw materials being under current evaluation for twin screw wet granulation processes within the NCE development unit of Boehringer Ingelheim Pharma GmbH \& Co. KG. Five wall material samples had therefore been manufactured by Three Tec $\mathrm{GmbH}$, Switzerland. These five samples were made of the two steel types (1.4404 or 1.4542). Both steel types were either used untreated or surface hardened by the described means (see Table V). Each of the five samples had an unpolished side and a polished side (exemplary shown for one sample in Fig. 3).

Table IV Wall Material Samples Placed on the Bottom of the Shear Cell of Set 1 (General Material Screening) with Material Specification, Surface Treatment, and Surface Roughness Ra $[\mu \mathrm{m}]$

\begin{tabular}{llll}
\hline Sample no & Material specification & Surface treatment & $\begin{array}{l}\text { Surface } \\
\text { roughness } \\
(\mu \mathrm{m})\end{array}$ \\
\hline 1 & Glass & Smooth (untreated) & Ra: 0.006 \\
2 & & Rough & Ra: 2.299 \\
3 & Plastic: PEEK & Smooth & Ra: 3.548 \\
4 & Steel type 1.4301 & Cold-rolled & Ra: 0.171 \\
5 & & Polished & Ra: 0.163 \\
\hline
\end{tabular}

Abbreviations: PEEK, Polyetheretherketone 
Table V Wall/Screw Material Sample Description of Set 2 (Specific Screw Materials) with Material Specification, Special Surface or Hardening Treatment, and the Surface Roughness Ra $[\mu \mathrm{m}]$

\begin{tabular}{|c|c|c|c|}
\hline Sample no & Material specification & Surface/hardening treatment & Roughness of final surface $(\mu \mathrm{m})$ \\
\hline 1 & Steel type 1.4404 & Unhardened & $\begin{array}{r}\text { Polished - Ra } 0.053 \\
\text { Unpolished - Ra } 0.782\end{array}$ \\
\hline 2 & & HARD-INOX ${ }^{\circledR}-\mathrm{S}$ hardened & $\begin{array}{r}\text { Polished - Ra } 0.091 \\
\text { Unpolished - Ra } 0.531\end{array}$ \\
\hline 3 & Steel type 1.4542 & Unhardened & $\begin{array}{r}\text { Polished - Ra } 0.531 \\
\text { Unpolished - Ra } 0.570\end{array}$ \\
\hline 4 & & Precipitation hardened & $\begin{array}{r}\text { Polished - Ra } 0.053 \\
\text { Unpolished - Ra } 0.610\end{array}$ \\
\hline 5 & & TiN layered & $\begin{array}{r}\text { Polished - Ra } 0.283 \\
\text { Unpolished - Ra } 0.812\end{array}$ \\
\hline
\end{tabular}

Abbreviations: TiN, titanium nitride
Fig. 3 Visual difference between the unpolished and polished surface of wall material testing inserts for one exemplary screw material sample (1.4404 unhardened); positioned on bottom of shear cell
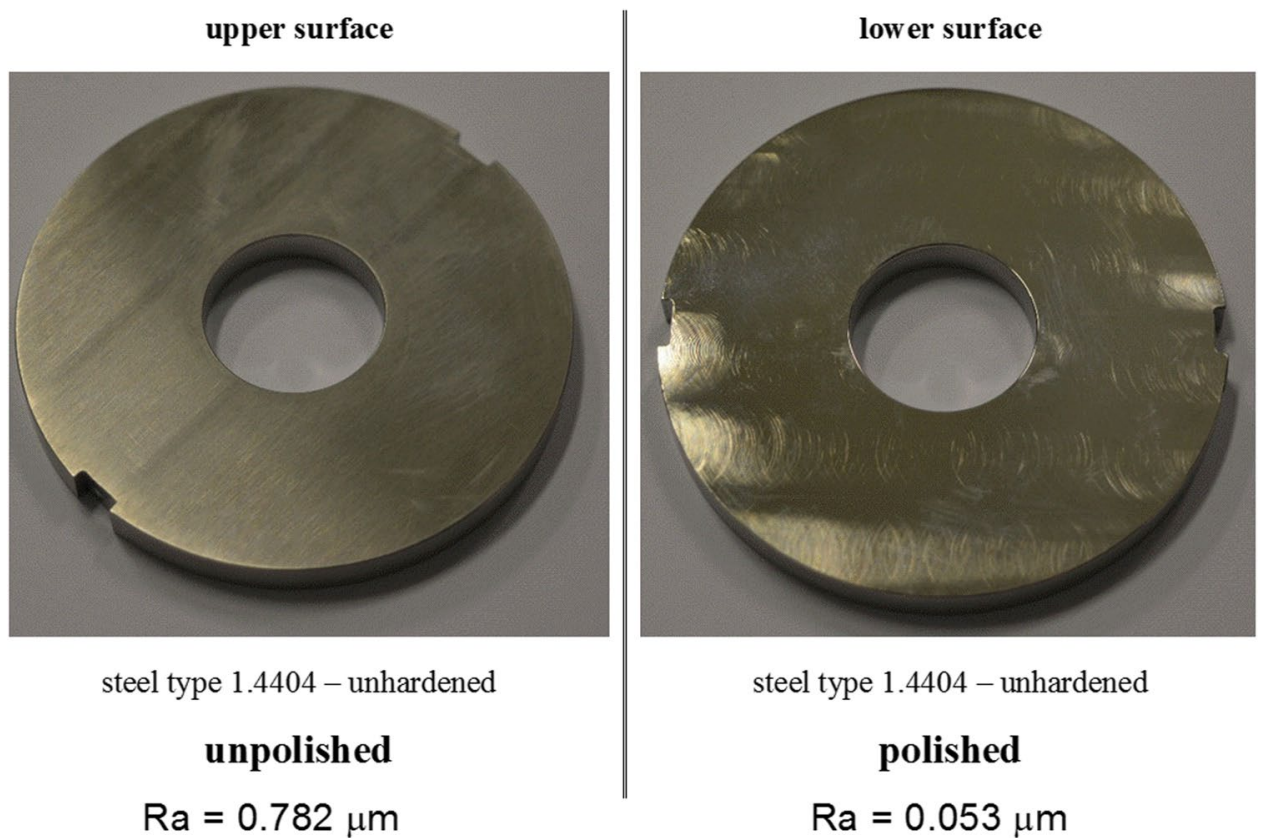

Table V shows the complete list of wall/screw material samples for set $2=$ evaluation set.

\section{Preparation of Wet Granule Mass for Wall Friction Measurement}

Wetting of dry powder material to result in a wet granule mass was performed by gentle blending and kneading using mortar and pestle. According to Eq. (2), the amount of needed water to be added to the dry powder preblend to result in a certain granulation moisture level ML [\%] was calculated. For the different formulations (see Tables I, II and III), different MLs were chosen as the evaluated formulations require different granulation MLs for successful granulation. For formulation 1 (see Table I), the MLs were ML1 $=0 \%$ (dry powder preblend), ML2 $=20 \%$, ML3 $=30 \%$, and ML4 $=40 \%$.
For formulation 2 (see Table II), the MsL were ML1 = $0 \%$ (dry powder preblend), ML2 $=10 \%$, ML3 $=15 \%$, and ML4=20\%.

For the BIxx1 formulation (see Table III), the investigated MLs were ML1 $=25 \%$ and ML2=30\%.

$$
\text { mass }_{\text {water }}[g]=\frac{\frac{M L[\%]}{100} * \text { mass }_{\text {powder }}[g]}{1-\frac{M L[\%]}{100}}
$$

\section{Twin Screw Wet Granulation Process}

Twin screw wet granulation experiments were performed using the BIxx1 formulation (see Table III). A ZE 16 granulator (Three-Tec GmbH, Switzerland) with a diameter of screws $\mathrm{D}=16 \mathrm{~mm}$ was used as twin screw granulator. The L/D-ratio (length-to-diameter-ratio) of the granulator was 
32. Screws were equipped with conveying elements only. For continuous feeding of the powder preblend into the granulator, a ZD12 flat bottom volumetric feeder (Three-Tec $\mathrm{GmbH}$, Switzerland) was applied. A peristaltic tube pump (Watson Marlow GmbH, Germany) was used for adding water as granulation liquid into the granulator.

The power consumption $[\mathrm{A}]$ was recorded during processing of at least several process parameter settings and enabled to calculate granulator torque for these settings. The specific mechanical energy was calculated according to Bochmann et al. [26].

\section{Visual Defect Rate of Tablets}

Visual defect rate of tablets was determined after tableting for a defined sample size $(n=200)$ which was appr. $6 \%$ of the total batch size in that case. The tablet sample was visually inspected from both sides and all tablets with slight spots as well as specks were sorted out. An example of how tablets with spots and specks looked like is given in Fig. 4.

\section{RESULTS}

\section{Wall Friction Measurement Method - Proof of Feasibility}

Figure 5 shows the interaction of placebo formulation 2 with the different wall materials of set 1 (see Table IV) at different granulation moisture levels $[\%(\mathrm{w} / \mathrm{w})]$ and normal stresses $\sigma_{\mathrm{w}}[\mathrm{Pa}]$.

A decrease of the average WFA $\varphi\left[^{\circ}\right]$ with increasing normal stress $\sigma_{w}[\mathrm{~Pa}]$ was observed. Furthermore, an increase of average WFA $\varphi\left[{ }^{\circ}\right]$ with increasing moisture level [\%] - compared at defined normal stresses $\sigma_{w}[\mathrm{~Pa}]$ - was obtained. These two effects were especially pronounced for steel with the two different surface treatments (polished and cold-rolled) and glass with a smooth surface. The plastic

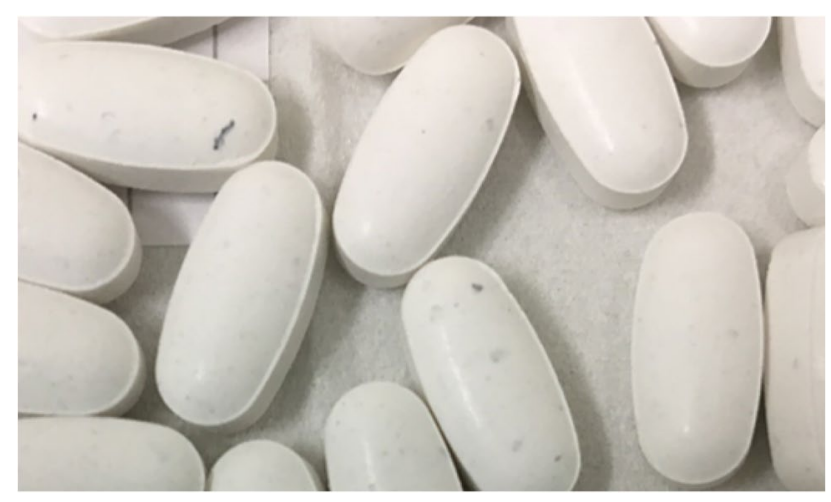

Fig. 4 Tablets with visual defects caused by abrasion effects during twin screw wet granulation process wall material PEEK (polyetheretherketone) and the glass material with roughened surface did not show a comparable strong effect of normal stresses $\sigma_{w}[\mathrm{~Pa}]$ and moisture level [\%] on average WFA $\varphi\left[^{\circ}\right]$. Additionally, differences in average WFA $\varphi\left[^{\circ}\right]$ were observed between the different wall materials and surface treatments at fixed normal stress $\sigma_{w}[\mathrm{~Pa}]$ and comparable moisture level [\%]. For example, at a normal stress $\sigma_{w}=200 \mathrm{~Pa}$ and a moisture level $\mathrm{ML}=15 \%$, the lowest WFAs $\left(\varphi=37^{\circ}\right.$ to $\left.40^{\circ}\right)$ were measured for the wall materials glass with roughened surface, the plastic PEEK, and the polished surface of the 1.4301 steel. A medium WFA $\left(\varphi=55^{\circ}\right)$ was measured for the cold-rolled surface of the 1.4301 steel. The highest WFA $\left(\varphi=77^{\circ}\right)$ was obtained for the glass material with a smooth surface.

Using an exemplary wall material (glass - roughened and smooth surface), Fig. 6 illustrates how differences in formulations affected the measured WFA $\varphi\left[^{\circ}\right]$.

Looking at the results of the average WFA $\varphi\left[{ }^{\circ}\right]$ at different moisture levels [\%] and normal stresses $\sigma_{w}[\mathrm{~Pa}]$ on smooth glass surface and roughened glass surface for both placebo formulations shows that average WFAs $\varphi\left[{ }^{\circ}\right]$ were lower on the roughened surface compared to the smooth surface irrespective of the investigated formulation. Furthermore, average WFAs $\varphi\left[{ }^{\circ}\right]$ were very similar for both formulations with regard to friction on the roughened glass surface. In contrast to that, pronounced differences between formulation 1 and formulation 2 were visible for the experiments performed on the smooth surface. Starting at $\mathrm{ML}=0 \%$, formulation 1 showed a maximum of WFA at a $\mathrm{ML}=20 \%$; at higher ML, lower WFA values were observed again. In contrast to that, formulation 2 showed a strong correlation of WFA $\varphi\left[{ }^{\circ}\right]$ and normal stress $\sigma_{w}[\mathrm{~Pa}]$, and moisture level [\%]. WFA $\varphi\left[{ }^{\circ}\right]$ steadily increased at decreasing normal stress $\sigma_{w}[\mathrm{~Pa}]$ and increasing moisture level [\%].

\section{Evaluation of Wall Friction Angle for Different Screw Materials and Formulations}

In a second step, experiments with samples made of different screw materials were conducted to check if the results from the method described in the previous chapter can be linked to the twin screw wet granulation process. The description of the wall/screw material set 2 can be found in Table V. The correlation of average WFA $\varphi\left[^{\circ}\right]$ and normal stress $\sigma_{w}$ $[\mathrm{Pa}]$ for both active formulations 1 and 2 (see Tables I and II), different moisture levels [\%], and all investigated screw materials of set 2 with polished surfaces is depicted in Fig. 7.

Except for formulation 2 in the interaction with TiN (titanium nitride)-layered type 1.4542 steel surface, the interactions between all other screw materials and both formulations resulted in decreasing average WFA $\varphi\left[^{\circ}\right]$ with increasing normal stress $\sigma_{\mathrm{w}}[\mathrm{Pa}]$ and decreasing moisture level [\%]. These correlations were also described for wall material set 1 . 
Fig. 5 Relationship between average wall friction angle WFA $\varphi\left[{ }^{\circ}\right]$ and normal stress $\sigma_{w}[\mathrm{~Pa}]$ for placebo formulation 2; error bars, $\pm 1 \mathrm{SD}(n=4)$; rows, wall materials; columns, moisture level [\%]

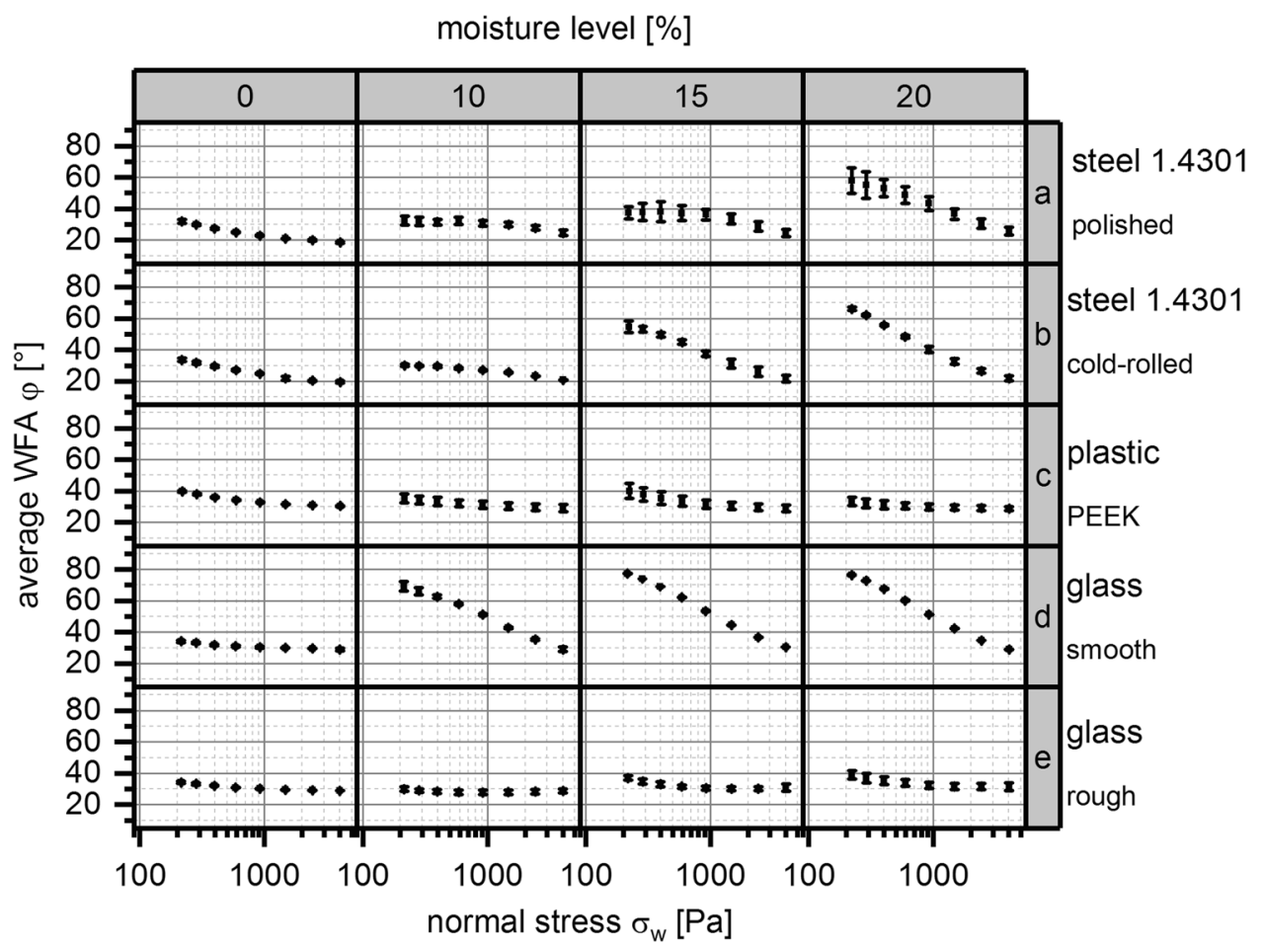

Nevertheless, differences of average WFA $\varphi\left[^{\circ}\right]$ could be detected as illustrated in Fig. 8.

WFAs $\varphi\left[{ }^{\circ}\right]$ did differ between formulations, screw materials, and surface treatments of these screw materials (polished $v s$. unpolished), as well as on moisture level [\%] and normal stress $\sigma_{w}[\mathrm{~Pa}]$. Two screw materials - steel type 1.4404 unhardened and steel type 1.4542 precipitation hardened - were exemplarily chosen for further evaluation of the TSG process.
Fig. 6 Relationship between average wall friction angle WFA $\varphi\left[^{\circ}\right]$, normal stress $\sigma_{w}[\mathrm{~Pa}]$, and different moisture levels [\%]; columns, glass surfaces; rows, placebo formulations 1 and 2

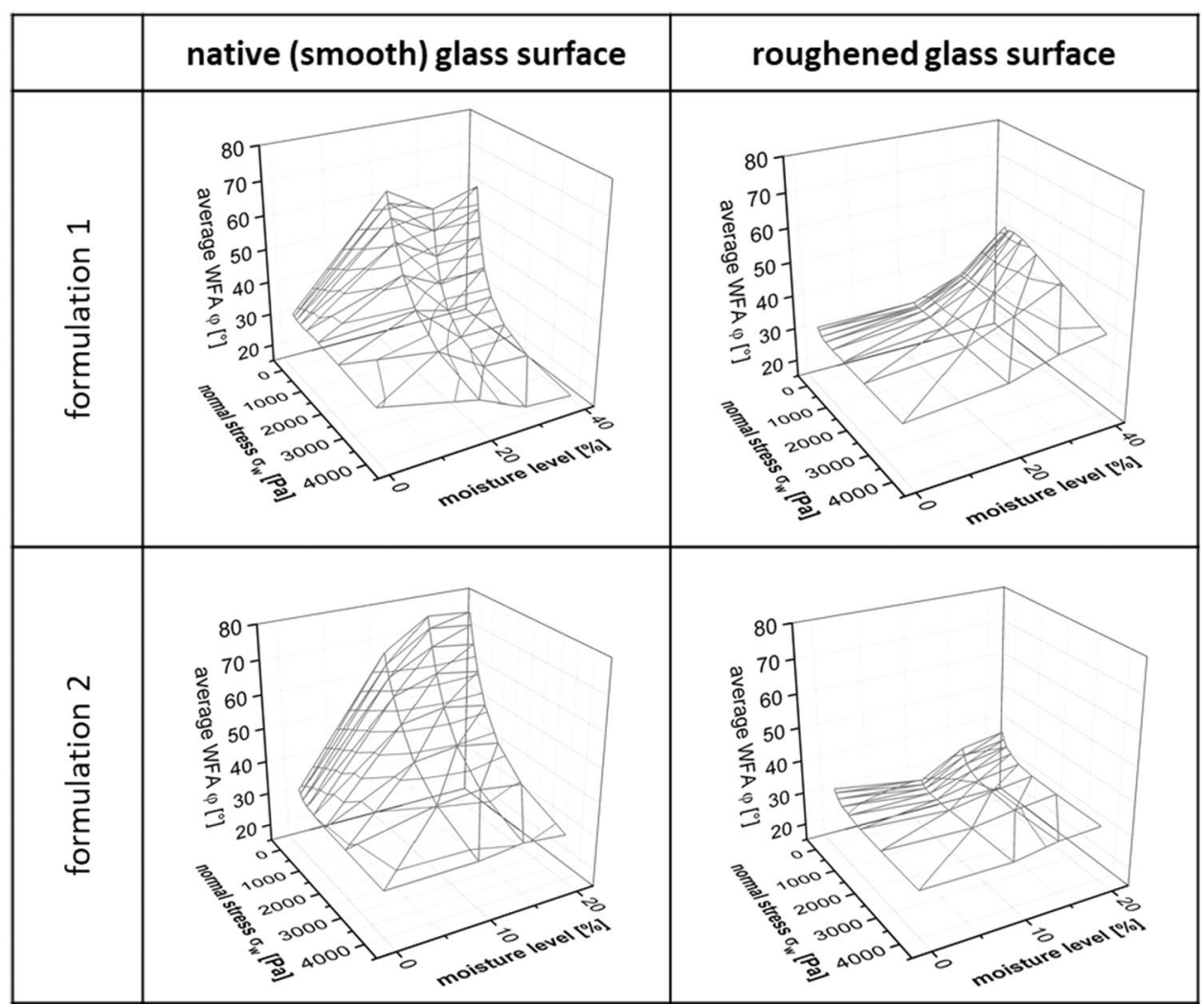


moisture level [\%]

Formulation 1

Formulation 2

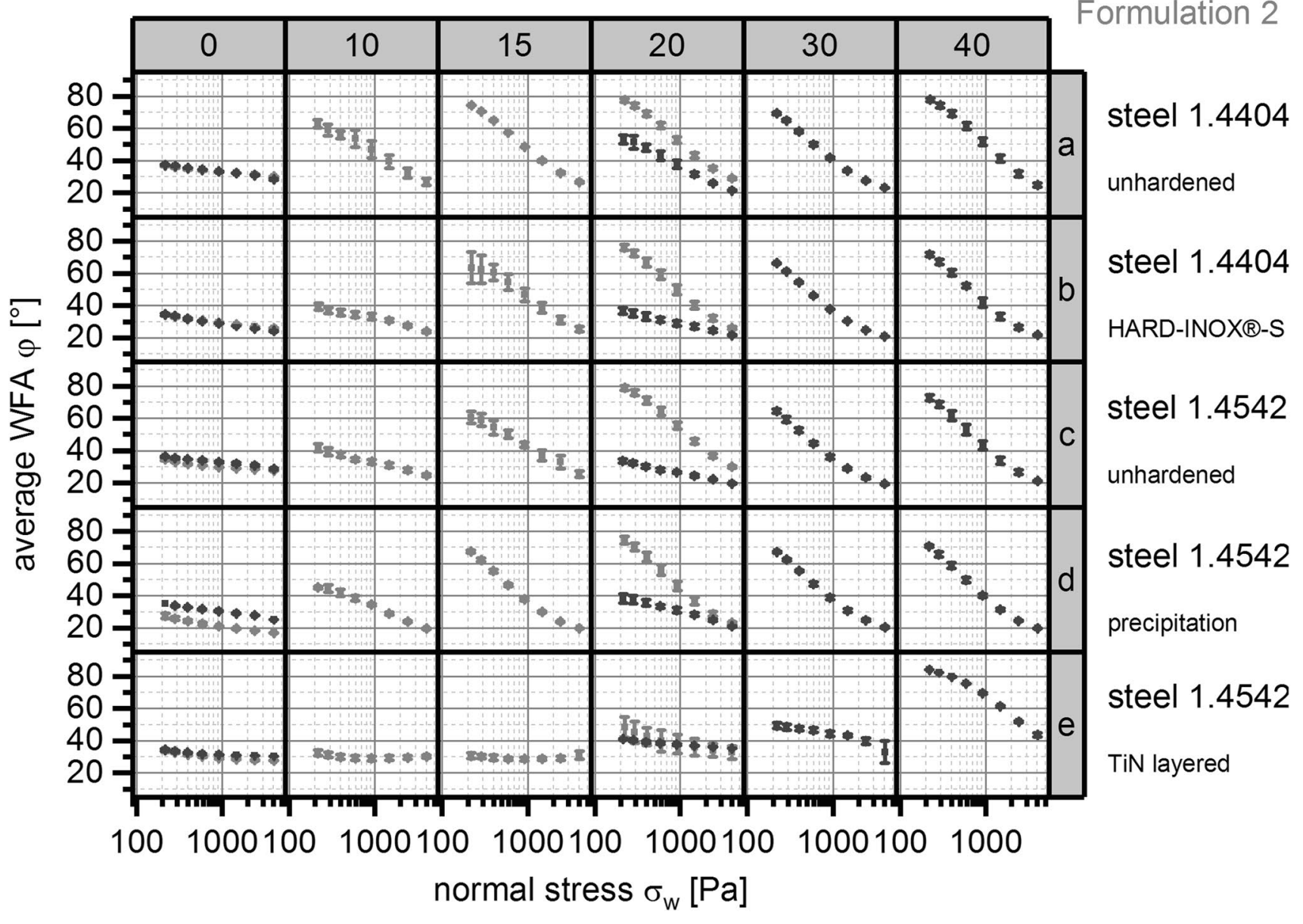

Fig. 7 Relationship between average wall friction angle WFA $\varphi\left[{ }^{\circ}\right]$ and normal stress $\sigma_{w}[\mathrm{~Pa}]$ for active formulation 1 and 2; error bars, \pm 1 SD $(n=4)$; columns, moisture levels [\%]; rows, screw materials with polished surface

Considering the surface roughness Ra of polished and unpolished materials, it was found that for almost all materials the values of Ra of polished surfaces are 10 times smaller compared to the unpolished. Different effects of the surface roughness on the WFAs of the evaluated two formulations were found. While formulation 1 did not show big differences between the two surface treatments, formulation 2 showed the "typical" correlations as described earlier between WFA and normal stress regarding moisture level for polished surfaces of screw material, but not for unpolished surfaces. Interestingly, the WFAs describing the interaction between formulation 2 and unpolished screw surfaces were comparatively low $\left(\varphi<50^{\circ}\right)$, showing a completely different 3D plot (see Fig. 8) when compared to their "polished" partner-experiment.

Comparing two specific screw materials with polished surfaces - type 1.4404 unhardened steel and type 1.4542 precipitation hardened steel - average WFA was lower for the type 1.4542 precipitation hardened steel screw than for the type 1.4404 unhardened steel screw. This observation was found for both formulations.

\section{Case Study}

\section{Abrasion Effects During TSG Process}

As described by Menth et al. [27], gray spots occurred on the surface of tablets made of TSG granules using the BIxx1 formulation as described previous. These spots resulted from gray discoloration of the powder accumulating as a film at the barrel wall during the TSG process and were suspected to result from abrasion effects. The resulting ratio of tablets showing visual defects was $46.5 \%$ related to all tested tablets, at the maximum (representative picture of tablets with visual defects, see Fig. 4). Several actions were taken to reach a ratio of being affected to be visually rated tablets below the specification limit of $6.5 \%$ of tablets. Table VI gives an overview on these actions.

Process parameters were adapted to result in higher shear forces by increasing the powder feed rate PFR $[\mathrm{kg} / \mathrm{h}]$ and screw speed [rpm]; this consequently resulted also in a higher filling level FL [\%]. Furthermore, granulation 
Fig. 8 Average wall friction angle WFA $\varphi\left[{ }^{\circ}\right]$ in relation to different normal stresses $\sigma_{\mathrm{w}}[\mathrm{Pa}]$ and moisture levels [\%]; rows, screw materials and surface treatments; columns, active formulations 1 and 2

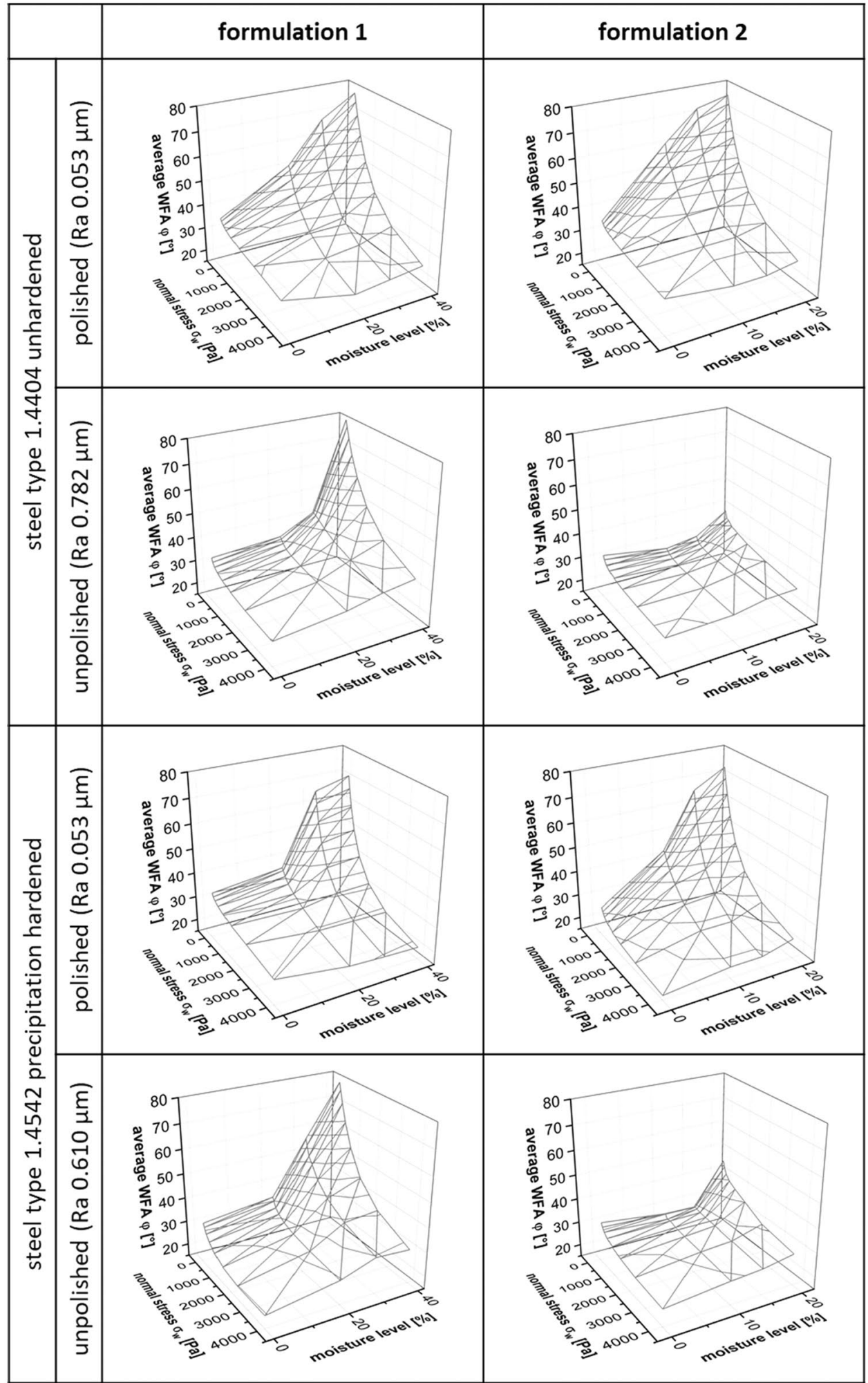

moisture level ML [\%] was increased. Granulator screws were exchanged as given in Table VI. An additional water cooling system was installed to the granulator barrel to keep the barrel temperature at a maximum of appr. $28^{\circ} \mathrm{C}$ even for process runs exceeding $15 \mathrm{~min}$.
The described optimizations to affect the smooth transport of wetted material do reflect the before mentioned reduction of WFAs and surprisingly did show a positive effect in the production process. 
Table VI Actions Taken to Improve TSG Process with Regard to Process Parameter Settings and Equipment Settings with the Aim to Minimize Visual Defect Rate of Resulting Tablets

\begin{tabular}{|c|c|c|c|}
\hline & & $\begin{array}{l}\text { Initial: visual defect rate of } \\
\text { tablets above specification } \\
\text { limit }\end{array}$ & $\begin{array}{l}\text { Improved: visual defect rate } \\
\text { of tablets below specification } \\
\text { limit }\end{array}$ \\
\hline \multirow{5}{*}{$\begin{array}{l}\text { Process parameter setting TSG } \\
\text { process }\end{array}$} & Powder feed rate PFR [kg/h] & 0.9 & 2.6 \\
\hline & Liquid feed rate LFR [kg/h] & 0.3 & 1.1 \\
\hline & Screw speed granulator [rpm] & 150 & 329 \\
\hline & $\begin{array}{l}\text { Granulation moisture level ML } \\
{[\%]}\end{array}$ & 25 & 30 \\
\hline & Filling level FL inside barrel [\%] & 6.5 & 8.6 \\
\hline \multirow[t]{2}{*}{ Equipment settings TSG process } & Granulator screws & $\begin{array}{l}\text { steel type: } 1.4404 \text { unhardened; } \\
\text { modular screw elements }\end{array}$ & $\begin{array}{l}\text { steel type: } 1.4542 \text { precipitation } \\
\text { hardened; monolithic screw }\end{array}$ \\
\hline & Cooling of barrel & No cooling & Water cooling \\
\hline
\end{tabular}

In summary, the sum of the actions was successful, resulting in a visual defect rate of the tested tablets within specification limit of lower than $6.5 \%$.

\section{Supportive Measurements Understanding TSG Process}

Evaluation of Granulator Torque Conductive power consumption measurements [A] of the twin screw granulator motor enabled granulator torque output [Nm] for several different process parameter settings. As presented in Fig. 9, the major impact on granulator torque is given by granulator screw speed. At a low screw speed of $150 \mathrm{rpm}$, the granulator torque reached its highest value $(12.9 \mathrm{Nm})$. For a middle screw speed of $300 \mathrm{rpm}$, a granulator torque range between 5.8 and $7.1 \mathrm{Nm}$ was reached. At the highest investigated screw speed of $500 \mathrm{rpm}$, the granulator torque decreased further to a range between 2.7 and $6.2 \mathrm{Nm}$.

This interesting observation led to the authors' expectation that wall friction measurements with a ring shear tester showing similar trends (decreasing abrasion at increasing normal stress) could serve as an additional supportive method addressing the explanation of abrasion effects inside TSG. The finding of decreasing torque at increasing screw speed was also investigated by several other research papers [22, 28, 29]. The influences of barrel filling level FL [\%] (affected by the changes in throughput) and granulation moisture level ML [\%] on granulator torque were only minor within this study.

Evaluation of WFA Measurements Using a Ring Shear Tester As already described previous, in addition to the evaluation of granulator torque $[\mathrm{Nm}]$, wall friction measurements with the BIxx1 formulation were conducted. The purpose of that measurements was to evaluate whether they may help to explain why the actions described in Table VI led to the improvement in terms of abrasion effects during TSG process. Figure 10 shows the results of wall friction measurements performed with a wet granule mass of the case study formulation at a $\mathrm{ML}=25 \%$. Average WFAs are plotted against normal stress for the two different screw materials used for the TSG process.

As expected, the average WFAs decreased for both screw materials with increasing normal stress. Comparing the screw materials, average WFAs for the precipitation hardened type 1.4542 steel screw were lower than for the unhardened type 1.4404 steel screw for all applied normal stresses.

In a second step, the impact of different granulation moisture level ML on average WFA was investigated. The interaction between the BIxx 1 formulation and the precipitation hardened type 1.4542 steel screw was measured at the two moisture levels ML1 $=25 \%$ and ML2 $=30 \%$.

As depicted in Fig. 11 for normal stresses, $\sigma_{w} 4<898 \mathrm{~Pa}$ WFAs are lower at ML1 $=25 \%$ than at ML2 $=30 \%$. At normal stresses $\sigma_{w} 4>898 \mathrm{~Pa}$, this relationship switches so that WFAs are a lower at ML2 $=30 \%$ than at ML1 $=25 \%$ but without showing any significant effects as standard deviations are overlapping for this second case.

\section{DISCUSSION}

The wall friction measurements with wall material set 1 (see Table IV), which offers a high variety of different wall materials in terms of surface roughness and treatment, showed the typical correlations between WFAs and normal stress as also described in literature [9], confirming the usability of wall friction measurements in this regard. Typically, WFA increases at decreasing normal stress, see also Fig. 5 for wall materials steel and smooth glass. Furthermore, granulation moisture level ML were identified to be of high impact on resulting WFAs as well, with WFAs typically increasing 
Fig. 9 Influence of granulator screw speed [rpm] on granulator torque $[\mathrm{Nm}]$ using BIxx1 formulation; colors, granulation moisture levels [\%]; bullet point size, barrel fill levels FL [\%]
Fig. 10 Average wall friction angle WFA $\varphi\left[{ }^{\circ}\right]$ vs. normal stress $\sigma_{w}[\mathrm{~Pa}]$ at given granulation moisture level for BIxx1 formulation; error bars, $\pm 1 \mathrm{SD}$ $(n=4)$; colors, screw materials

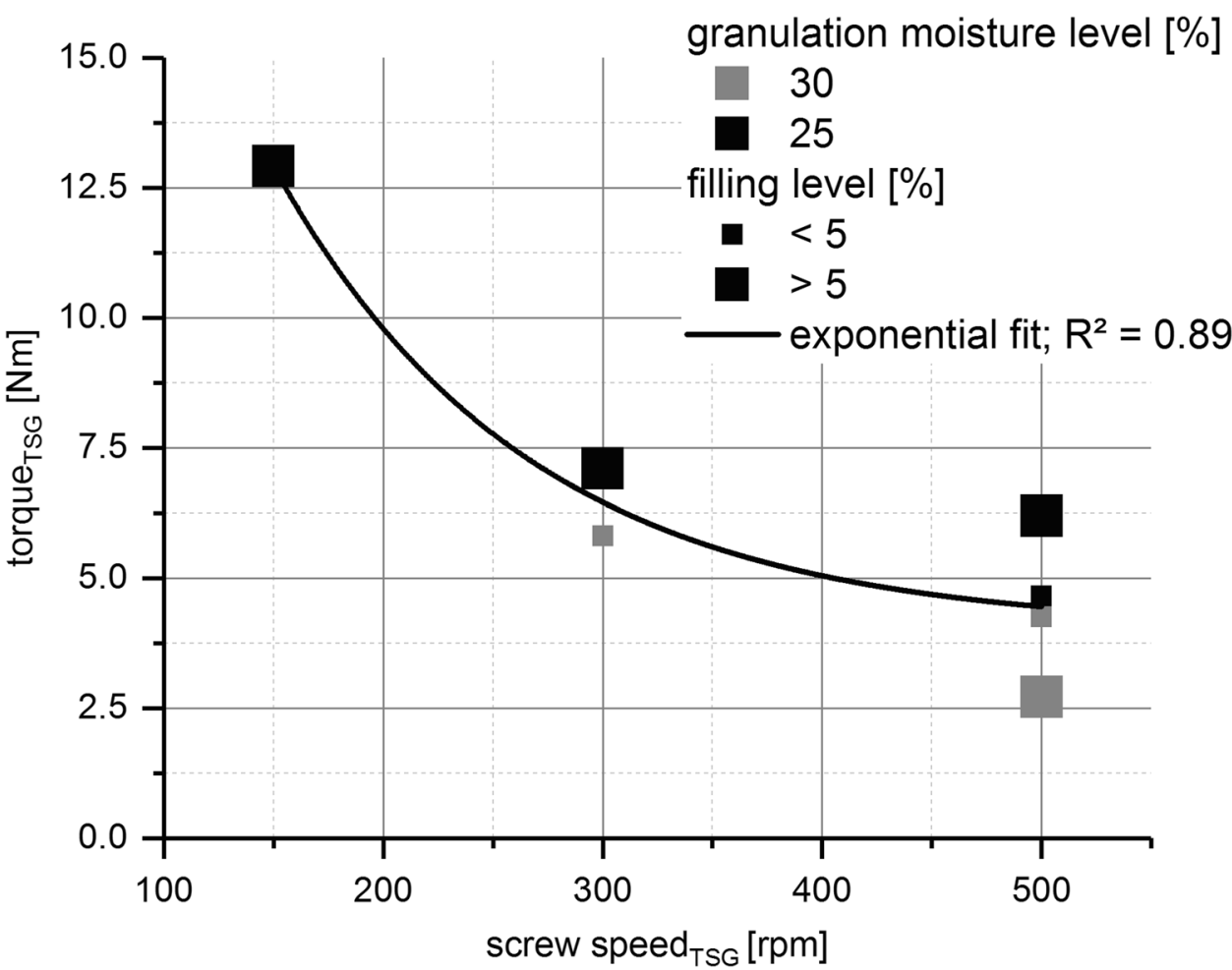

moisture level $=25 \%$

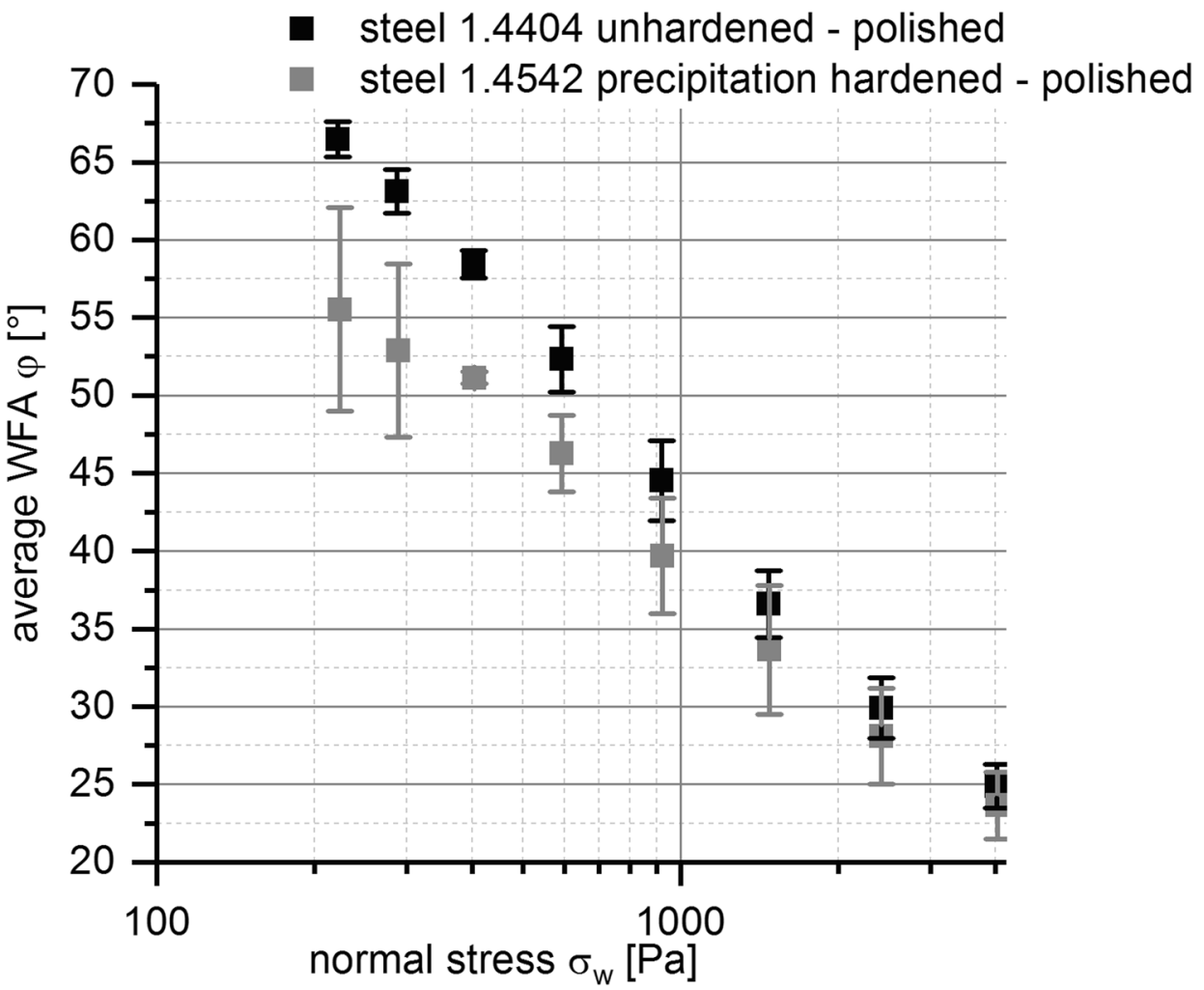

with increasing ML (see also Fig. 5). But within this investigation, some exceptions to these two described correlations were observed. For example, the WFAs measured on the wall material plastic PEEK and the glass material with roughened surface were shown to be quite independent of normal stress (see Fig. 5). Another exception occurred. 
Fig. 11 Average wall friction angle WFA $\varphi\left[{ }^{\circ}\right] v s$. normal stress $\sigma_{\mathrm{w}}[\mathrm{Pa}]$ at given screw material for BIxx1 formulation; error bars, $\pm 1 \mathrm{SD}(n=4)$; colors, moisture levels $(\%)$

\section{screw material: steel 1.4542 precipitation hardened}

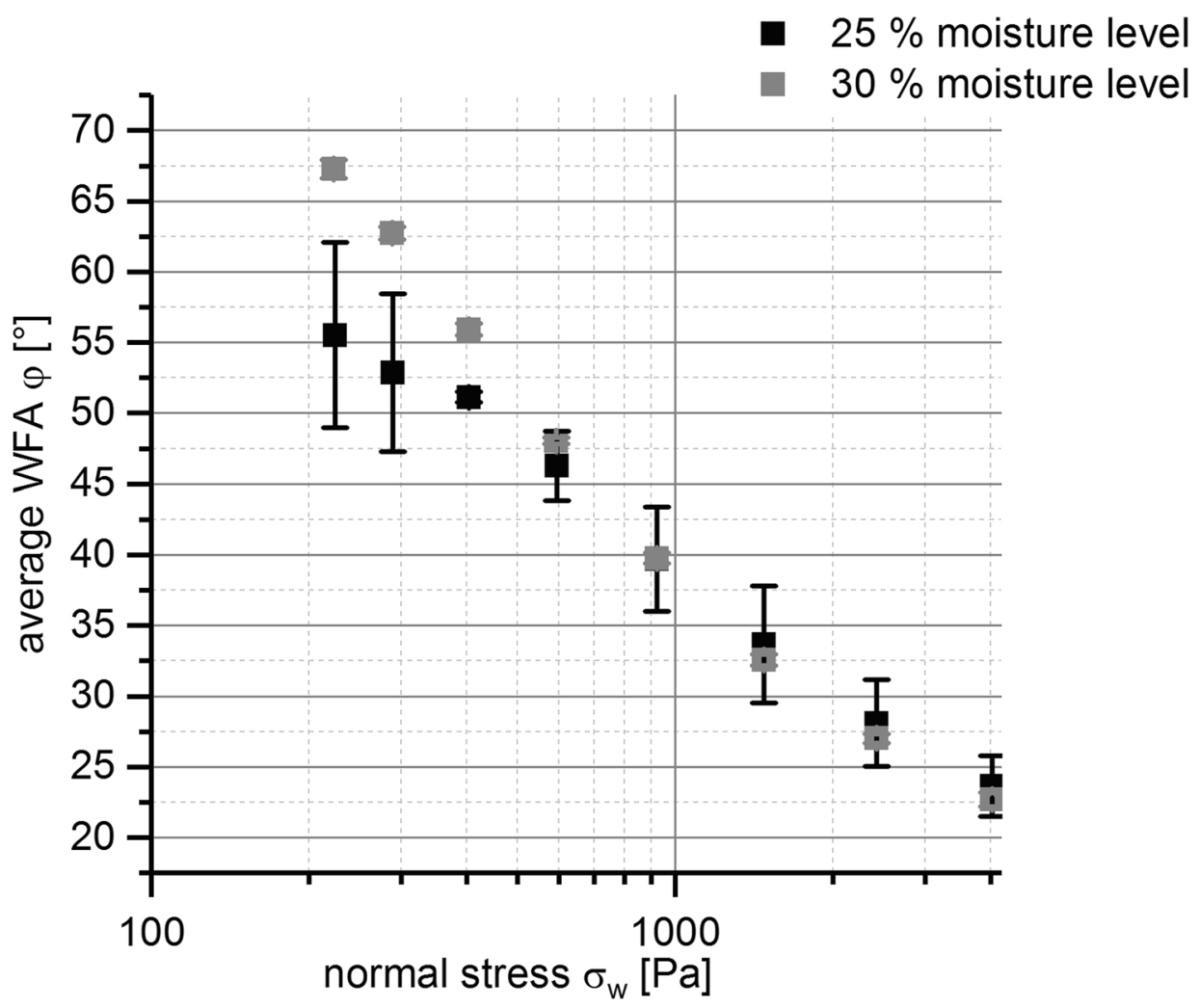

Formulation 1 resulted in a maximum WFAs on the glass material with smooth surface at a $\mathrm{ML}=20 \%$, as depicted in Fig. 6. For increasing normal stress at MLs $>20 \%$, the WFAs was either further decreasing or remaining on an equal level when compared to a $\mathrm{ML}=20 \%$. The authors expect the "sponge" effect of cellulose [30] being part of formulation $1(31.5 \%(\mathrm{w} / \mathrm{w}))$ to be responsible for the described effect, as uptaken water might be released under pressure and shear conditions. This leads to a decrease of wall friction angle dependent on moisture level ML and at increased normal stress.

In the presented work, the WFA method was evaluated regarding its ability to differentiate between different wall materials, surface treatments of wall materials, and formulations.

As wall materials from set 1 were successfully differentiated by the method, experiments were conducted to test screw material set 2 (see Table V). In contrast to wall material set 1 , screw material set 2 was much more similar in terms of surface roughness, and treatment. Nevertheless, the impact of normal stress, ML, screw materials including their surface treatment, and formulations on WFA could be measured and differentiated with screw material set 2 as well (see Fig. 7). The TiN-layered screw material showed potential advantages in terms of lower WFAs independent of normal stress in most instances. The evaluation of the two screw materials unhardened 1.4404 steel $v s$. precipitation hardened
1.4542 steel showed the advantage of precipitation hardened 1.4542 steel screw in terms of friction.

Finally, the case study presented enabled to figure out the connections between all evaluated modules:

- abrasion effects occurring inside TSG resulting in a high visual defect rate of tablets

- adaption of process parameter and equipment settings to minimize these abrasion effects

- granulator torque

- wall friction angle

A clarification of these connections is depicted in Fig. 12 and Table VII. Calculation of specific mechanical energy for the granulator (SME) $[\mathrm{kWh} / \mathrm{t}]$ offered the possibility to evaluate the influence of granulator screw speed, adaption of powder feed rate, and granulator torque at a specific screw speed (based on the relationship found in Fig. 9) on the improvement of tablets' visual defect rate.

Comparing SME value for initial and improved process settings, a decrease of SME to $34.8 \%$ for the improved process settings $(\mathrm{SME}=78 \mathrm{kWh} / \mathrm{t})$ compared to the initial process setting $(\mathrm{SME}=225 \mathrm{kWh} / \mathrm{t})$ was calculated. The same trend could be figured out within the wall friction measurement. Within the applied range of normal stresses (200-4000 Pa), a decrease of the wall friction angle to $34.1 \%$ of WFAs $\left(23^{\circ}\right)$ at highest normal stress of $4000 \mathrm{~Pa}$ compared 


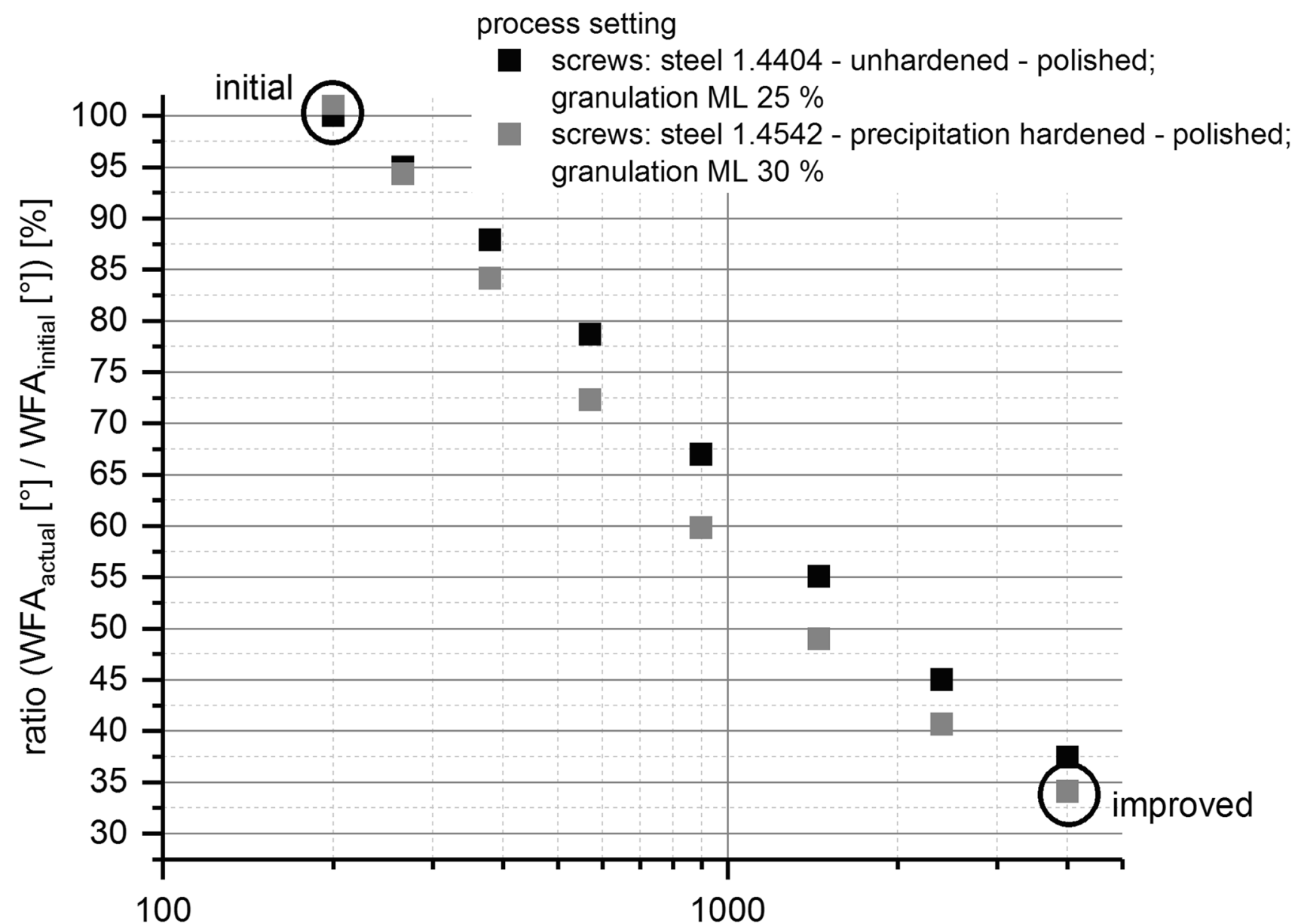

\section{normal stress $\sigma_{\mathrm{w}}[\mathrm{Pa}]$}

Fig. 12 Decrease of measured wall friction angle WFA $\left[{ }^{\circ}\right]$ with a ring shear tester using improved process settings; colors, black - initial settings; gray - improved settings

to the WFAs $\left(66^{\circ}\right)$ obtained at lowest applied normal stress (200 Pa) could be found (see Fig. 12 and Table VII), too.

Furthermore, with the help of WFA measurements, additional information with regard to exchange of screw material and adaption of granulation moisture level ML could be evaluated. The advantage of the type 1.4542 steel screws with precipitation hardened surface compared to the type 1.4404 unhardened steel screws in terms of friction and improvement of tablets' visual

Table VII Relation Between Specific Mechanical Energy (SME) $[\mathrm{kWh} / \mathrm{t}]$ (TSG), Measured Wall Friction Angles (WFA) $\left.{ }^{\circ}\right]$ (Ring Shear Tester), and Resulting Defect Rate [\%] (Tablets) for Initial and Improved Process Settings

\begin{tabular}{lll}
\hline Initial & & Improved \\
\hline 225 & $\begin{array}{l}\text { TSG } \\
\text { Specific mechanical energy SME } \\
\\
\quad[\mathrm{kWh} / \mathrm{t}]\end{array}$ & 78 \\
66 & $\begin{array}{l}\text { Ring shear tester } \\
\text { Wall friction angle WFA }\left[^{\circ}\right]\end{array}$ & 23 \\
46.5 & $\begin{array}{l}\text { Tablets } \\
\text { Visual defect rate }\end{array}$ & $<6.5$ \\
& & \\
\hline
\end{tabular}

defect rate could be shown. WFAs were lower for measurements using the improved screw material compared to measurements conducted with the initial screw material within the whole applied normal stress range (see Fig. 10). The evaluation of the impact of granulation moisture level (ML) on WFAs showed that increasing ML led to either a decrease or increase of WFAs and was dependent on applied normal stress (see Fig. 11). Therefore, the impact of ML on improvement of tablets' visual defect rate seems to be minor compared to the adaption of the other process parameter settings and the exchange of the screw pair.

All in all, the case study showed that WFA measurements could serve as a base for explanation and justification of the several actions conducted to improve tablets' visual defect rate (see Table VI) as the correlation to the TSG process could be shown evaluating granulator torque and calculating SME. Adapting process parameter settings by increasing screw speed, throughput and fill level of the granulator as well as adapting equipment settings by exchanging screw material were found to have a high impact on improving abrasion effects inside TSG. Therefore, WFA measurements 
were shown to be a helpful tool for the assessment of abrasion induced effects inside TSG - either for troubleshooting purposes or already at the start of any experiments.

\section{CONCLUSION}

An extensive evaluation of WFA measurements using the Schulze ring shear tester for different wall and TSG screw material samples and three different formulations was performed. In addition, the impact of normal stress $\sigma_{w}$ as well as granulation moisture level ML on WFAs was investigated for the combination of different wall/screw material samples and different formulations. As expected, WFAs was found to differ depending on combinations of wall/screw material and formulation.

WFA measurements with the different screw materials showed that precipitation-hardened 1.4542 steel screws and TiN-layered 1.4542 steel screws outperformed other screw materials in terms of low WFAs. Therefore, these two screw materials should be preferred for use in TSG process to minimize abrasion effects. In retrospect, WFA measurements helped to understand the successful trouble shooting actions minimizing abrasion effects in a specific case study. WFA measurements gave mechanistic explanations and confirmed the process parameter and equipment changes to the TSG process.

For the future, this application of WFA measurement for TSG screw materials can serve as an easy tool for all stages of pharmaceutical development of new chemical entities as only low amount of drug substance is needed. Based on these measurements, a reasonable decision on TSG equipment material as well as process parameter settings should be possible already at the start of drug product development increasing process knowledge at reduced process risks, i.e., improving quality by design.

Author Contribution Judith Menth: conceptualization - methodology - investigation - writing of the original draft.

Martin Maus: conceptualization - methodology - resources review of the original draft.

Karl Gerhard Wagner: conceptualization - methodology- review of the original draft - supervision.

Funding Open Access funding enabled and organized by Projekt DEAL. This study was performed in cooperation between University of Bonn and Boehringer Ingelheim Pharma GmbH \& Co.KG. No additional funding was applied.

\section{Declarations}

Conflict of Interest The authors declare no competing interests.
Open Access This article is licensed under a Creative Commons Attribution 4.0 International License, which permits use, sharing, adaptation, distribution and reproduction in any medium or format, as long as you give appropriate credit to the original author(s) and the source, provide a link to the Creative Commons licence, and indicate if changes were made. The images or other third party material in this article are included in the article's Creative Commons licence, unless indicated otherwise in a credit line to the material. If material is not included in the article's Creative Commons licence and your intended use is not permitted by statutory regulation or exceeds the permitted use, you will need to obtain permission directly from the copyright holder. To view a copy of this licence, visit http://creativecommons. org/licenses/by/4.0/.

\section{References}

1. Stauffer F, Ryckaert A, Hauwermeiren DV, Funke A, Djuric D, Nopens I, et al. Heat transfer evaluation during twin-screw wet granulation in view of detailed process understanding. AAPS PharmSciTech. 2019;20(7):291.

2. Berry RJ, Bradley MSA, Reed AR, Farnish RJ, Angulo OA. Development of an annular wall friction tester and test procedure, suitable for equipment design and powder characterisation. 9th International Conference on Bulk Materials Storage, Handling and Transportation, ICBMH. 2007.

3. Bradley MSA, Bingley MS, Pittman AN. Abrasive wear of steels in handling of bulk particulates: an appraisal of wall friction measurement as an indicator of wear rate. Wear. 2000;243:25-30.

4. Bradley MSA, Pittman AN, Bingley M, Farnish RJ, Pickering J. Effects of wall material hardness on choice of wall materials for design of hoppers and silos for the discharge of hard bulk solids. Tribol Int. 2000;33:845-53.

5. Fekete R, Peciar M, Hanzel M. Influence of powder material moisture on the angle of wall friction. Part Part Syst Charact. 2007;24:276-83.

6. Haaker G. Wall friction measurements on bulk solids - results of comparative measurements on 9 bulk-solid/wall combinations from 13 laboratories using the Jenike Sheartester. Powder Handling and Processing. 1999;11:19-25.

7. Halford W, Lawler C, Grima AP, Arnold PC. Some influences on wall friction measurements - a preliminary investigation. 11th International Congress on Bulk Material Storage, Handling and Transportation, University of Newcastle 2013. pp. 1-10.

8. Han T. Comparison of wall friction measurements by jenike shear tester and ring shear tester. Kona Powder Part J. 2011;29:118-24.

9. Hancock BC. The wall friction properties of pharmaceutical powders, blends, and granulations. J Pharm Sci. 2019;108:457-63.

10. Iqbal T, Fitzpatrick JJ. Effect of storage conditions on the wall friction characteristics of three food powders. J Food Eng. 2006;72:273-80.

11. Jager PD, Bramante T, Luner PE. Assessment of pharmaceutical powder flowability using shear cell - based methods and application of Jenikes methodology. J Pharm Sci. 2015;104:3804-13.

12. Pillai JR, Bradley MSA, Berry RJ. Comparison between the angles of wall friction measured on an on-line wall friction tester and the Jenike wall friction tester. Powder Technol. 2007;174:64-70.

13. Prescott JK, Ploof DA, Carson JW. Developing a better understanding of wall friction. powder handling \& processing. 1999;11:27-36.

14. Behres M, Klasen CJ, Schulze D. Development of a shear cell for measuring the wall friction of bulk solids with a ring shear tester. Powder Handling and Processing. 1998;10:405-9.

15. Schulze D. Pulver und Schüttgüter - Fließeigenschaften und Handhabung. Heidelberg: Springer Verlag; 2014.

16. Desbois L, Tchoreloff P, Mazel V. Influence of the punch speed on the die wall/powder kinematic friction during tableting. J Pharm Sci. 2019;108:3359-65. 
17. Mazel V, Diarra H, Tchoreloff P. Effect of friction between powder and tooling on the die-wall pressure evolution during tableting: experimental and numerical results for flat and concave punches. Int J Pharm. 2019;554:116-24.

18. Nakamura S, Otsuka N, Yoshino Y, Sakamoto T, Yuasa H. Predicting the occurrence of sticking during tablet production by shear testing of a pharmaceutical powder. Chem Pharm Bull. 2016;64:512-6.

19. Snick BV, Grymonpré W, Dhondt J, Pandelaere K, Pretoro GD, Remon JP, et al. Impact of blend properties on die filling during tableting. Int J Pharm. 2018;549:476-88.

20. Lee SL, O'Connor TF, Yang X, Cruz CN, Chatterjee S, Madurawe $\mathrm{RD}$, et al. Modernizing pharmaceutical manufacturing: from batch to continuous production. J Pharm Innov. 2015;10:191-9.

21. Zhang Y, Liu T, Kashani-Rahimi S, Zhang F. A review of twin screw wet granulation mechanisms in relation to granule attributes. Drug Dev Ind Pharm. 2021;47(3):349-60.

22. Kumar A, Vercruysse J, Toiviainen M, Panouillot PE, Juuti M, Vanhoorne V, et al. Mixing and transport during pharmaceutical twin-screw wet granulation: experimental analysis via chemical imaging. Eur J Pharm Biopharm. 2014;87:279-89.

23. Köster C, Pohl S, Kleinebudde P. Evaluation of binders in twinscrew wet granulation. Pharmaceutics. 2021;13:241.

24. Vandevivere L, Vangampelaere M, Portier C, de Backere C, Häusler O, De Beer T, et al. Identifying critical binder attributes to facilitate binder selection for efficient formulation development in a continuous twin screw wet granulation process. Pharmaceutics. 2021;13:210.

25. Schulze, D. Flow properties of powders and bulk solids. Technical paper. https://www.dietmar-schulze.de/grdle1.pdf (accessed 22 January 2021).

26. Bochmann E, Gryczke A, Wagner K. Validation of model-based melt viscosity in hot-melt extrusion numerical simulation. Pharmaceutics. 2018;10(3):132.

27. Menth, J, Maus M, Wagner KG. Establishing twin screw wet granulation (TSG) as a continuous process step. Abstract and poster presentation, APV World Meeting, Granada; 2018

28. Dhenge RM, Fyles RS, Cartwright JJ, Doughty DG, Hounslow MJ, Salman AD. Twin screw wet granulation: granule properties. Chem Eng J. 2010;164:322-9.

29. Vanhoorne V, Vanbillemont B, Vercruysse J, Leersnyder FD, Gomes P, Beer TD, et al. Development of a controlled release formulation by continuous twin screw granulation: influence of process and formulation parameters. Int J Pharm. 2016;505:61-8.

30. Fielden KE, Newton JM, O'Brien P, Rowe RC. Thermal studies on the interaction of water and microcrystalline cellulose. J Pharm Pharmacol. 1988;40:674-8.

Publisher's Note Springer Nature remains neutral with regard to jurisdictional claims in published maps and institutional affiliations. 